\title{
CONTRASTES E CONFRONTOS ENTRE PRINCIPIOS E OBJETIVOS DA PÓS-GRADUAÇÃO EM MEDICINA TROPICAL ${ }^{1}$
}

\author{
Jayme Neves ${ }^{2}$
}

A implantação do sistema de pós-graduação, no seu sentido restrito, nas áreas biomédicas e em particular na medicina, tem constituido motivo de ampla discussão e, por via de conseqüência, tem também gerado um farto material muito útil para estudos e reflexões. Este material se encontra disponivel em registros de simpósios sistematizados, em múltiplas reuniões de sociedades e congressos médicos específicos, em anais de ensino, em publicações de instituições de pesquisa e, obviamente, em vários Pareceres do Conselho Federal de Educação. Na opinião de alguns estudiosos, estas discussões, que ainda hoje se travam, resultam de uma dificuldade básica maior, qual seja a falta de entedimento adequado, por parte do pessoal docente nessas áreas, sobre os objetivos reais do sistema de pós-graduação. Ainda que o sistema continue a absorver a atenção de educadores e autoridades de ensino, com o intúito fundamental de aclarar dilemas e solucionar desafios - naturalmente emergentes da implantação da nova sistemática-, vale enfatizar aqui que os objetivos dos cursos de pós-graduação, conforme definidos pela política operacional dos setores educacionais e da saúde são os seguintes:

1. Formar professorado competente capaz de atender à expansão quantitativa de nosso ensino superior.

2. Estimular o desenvolvimento da pesquisa científica.

3. Assegurar o treinamento de técnicos de alto padrão para fazer face às necessidades do desenvolvimento nacional.

E natural e perfeitamente compreensivel que as discussões e os debates, que até então se travaram, ao longo de mais de uma dezena de anos, não se tenha restringido, exclusivamente, aos princípio e objetivos da pós-graduação nas áreas biomédicas. Embora não seja nosso interesse reabrir aqui a discussão sobre um variado matiz de questionamentos e, diga-se de passagem, em sua grande maioria inteiramente pertinentes, vejamos, à guisa de ilustração, os temas considerados mais importantes nesses debates:

- estrutura e organização dos cursos; definição da Residência até sua atuał localização no senso lato da pós-graduação;

- relação dos cursos de pós-graduação com os de graduação;

- conceituação de educação formal versus educação informal;

- aquisição da titulação pós-graduada como requisito de progressão funcional do docente;

- acertos e desacertos da Reforma Universitária;

- deslocamento do foco da graduação para o mestrado, com riscos de transformar a pósgraduação em atividade suplementar de cursos de graduação deficientes;

- longa duração dos cursos de pós-graduação no sentido estrito em relação aos de outras áreas de conhecimento;

- temor quanto a possibilidade de os cursos pós-graduados serem subvertidos pela caça aos créditos;

- separação dos institutos centrais e suas implicações sobre a pesquisa aplicada na área profissional;

1. Traba/ho apresentado no XVIII Congresso da Sociedade Brasileira de Medicina Tropical, fevereiro, 1 a 6 , Ribeirão Preto, São Paulo, 1982.

2. Professor Titular de Doenças Infectuosas e Parasitárias da Faculdade de Medicina da Universidade Federal de Minas Gerais, Belo Horizonte, MG.

Endereço para correspondência: Prof. Jayme Neves, Rua São João Evangelista 849, Santo Antônio 30000 - Belo Horizonte, MG. 
- importância do desenvolvimento da criatividade cientifica;

- integração versus desintegração vertical e suas conseqüências na pesquisa de interesse multid isciplinar :

- hegemonia da investigação científica nas áreas básicas versus irrelevância da pesquisa aplicada;

institucionalização da pesquisa nos hospitais universitários;

aspectos éticos e legais das pesquisa nas áreas de aplicação profissional:

atrelamento da pesquisa científica à tecnologia de desenvolvimento econômico;

prioridades de financiamento da pesquisa aplicada, prospectiva e lúdica;

características do professor orientador de curso e de teses;

dedicação exclusiva do professor e do aluno na atividade pós-graduada;

Remuneração condigna do pessoal docente; privatização do magistério nos cursos de pós-graduação versus sobrecarga de funções docentes e administrativas;

aproveitamento dos pós-graduandos nas Universidades e inst ituições isoladas;

- condições de trabalho dos pós-graduandos que adquiriram competência na pesquisa.

A ordem com que as questões foram acima apresentadas nada tem a ver com sua magnitude $e$ importância nos diversos cursos na área médica, incluindo a medicina tropical, em funcionamento no país. Como há diferenças sensiveis entre os diversos sistemas de pós-graduação - dada a diversificação de problemas de educação médica, de politica de saúde e seus vínculos com a pesquisa, - pode-se perceber a primazia de alguns temas, que são comuns a todos os cursos; por outro lado, outros temas são peculiares a determinados cursos e, por isso, de interesse mais restrito, quando não episódico e temporal. O que importa assinalar, entretanto, é que todos estes questionamentos foram e continuam sendo motivos de debate e de discussão, o que garante, em última análise, o contínuo aperfeiçoamento do sistema, através de identificação e busca permanentes de correções para as distorções do seu processo. Dentre todos os temas, todavia, alguns têm merecido justificada prioridade nas discussões, tendo em vista certos temores, por parte dos órgãos governamentais, quanto à progressiva deterioração dos cursos de pós-graduação, em particular os da área clínica. Destaquemos alguns deles, de preferência os que enfatizam a necessidade de se manterem os padrões de qualidade dos cursos em funcionamento.
O PAPEL DA PÓS-GRADUAÇÃO NO DESEN. VOLVIMENTO DA CRIATIVIDADE CIENTIFICA

A discussão deste tema tem conduzido a um consenso da maioria dos participantes dos debates. Todos concordam com a assertiva do Prof. Rocha e Silva de constituir a criatividade científica a "verdadeira alma do sistema de pósgraduação". E é justamente por constituir a alma mater do sistema é que a entendemos como um poderoso agente de mudança. Como organização sistemática, poderá erguer-se sobre base sólida e larga, rompendo-se com a fase contemplativa e/ou com a visão quase patológica das idéias gerais, ainda que filhas da experiência da intuição. Erigindo uma fase construtiva, ela deverá minimizar os "inconvenientes do individualismo assistemático", preocupando-se com as idéias cientificas, e filhas do método (Bouglé).

E o caminho que segue o espirito humano para chegar à descoberta da verdade é essencialmente o mesmo, qualquer que seja a natureza dos fenômentos ou campos de estudo a que se aplica a investigação. A pós-graduação deverá demonstrar que, a rigor, em todas as ciências só há um método e que este se procede em três etapas: a) observações dos fatos direta e objetivamente, com afastamento sistemático de todas as pré-noções; b) concepção de uma explicação (hipótese) que permita ligar entre si certos grupos de fatos em relação à causa e efeito; c) verificação, "se não pela experimentação propriamente dita, ao menos pela observação conduzida de maneira especial" da hipótese que se formulou, se ela corresponde exatamente aos fatos.

Desafortunadamente, muitas de nossas instituições de ensino e pesquisa, hoje ingressadas ou postulantes ao sistema de pós-graduação, estabilizaram a marcha da descoberta da verdade na etapa da observação: da observação empírica, baseada, muitas vezes, em elementos subjetivos que, pela sua natureza, são inseguros e não inteiramente confiáveis. $O$ homem da ciência não cai sobre os fatos novos ou sobre as conclusões novas por acidente; ele só encontra o que observa, mas quando sabe o que procura. Impõese, nesta linha de idéias, a necessidade de aliar à experiência o experimento, na medida em que a primeira seja atendida como acúmulo de conhecimentos, de hábitos e de vivência e o segundo, como define Claude Bernard, "como uma observação provocada pelo investigador para por em prova uma idéia antecipada".

A institucionalização da criatividade cientifica em nossas instituições de ensino constitui 
objetivo primordial da pós-graduação. A tarefa é das mais árduas, mas dela dependerá a própria sobrevivência das instituições. É natural, conforme assinala o Prof. Paiva, da Faculdade de Medicina de Ribeirão Preto, que se tenha "medo de que a notória tendência latina para a erudição livresca acabe afogando o aluno de pós-graduação em cursos, relegando a um segundo plano a realização da pesquisa científica, que é mais difícil de ensinar e de se aprender e que é, realmente, o objetivo principal da pós-graduação. E para tornar o ensino menos verbal, menos abstrato, menos livresco, a primeira condição, assim enten-、 demos, deve ser o contato com os fatos e com os problemas atuais do meio, pela observação e pela pesquisa em todos os campos favoráveis às investigações dos fenômenos da saúde no contexto social em que vive o aluno, fazendo-o compreender o valor e o alcance dos fatos. Caso contrário, se movimentará, inapelavelmente, num horizonte estreito de informações e de erudição e, ipso facto, sem perspectivas para o trabalho cientifico essencialmente criador. Cada aluno deve ser emulado a sentir que todo o problema exige uma solução e que "é a exigência da solução do problema que constitui o fator orientador em todo o processo de reflexão (J. Dewey).

Foi estritamente por fidelidade à coerência que, em 01.08.78, encontrando-se já o Curso de Pós-Graduação em Medicina Tropical da UFMG no bojo de uma crise institucional, endereçamos ao Sr. Chefe do Departamento de Clínica Médica um longo arrazoado onde se lê (A verdade sobre a crise da Pós-Graduação em Medicina Tropical da Faculdade de Medicina da UFMG: o processo de desativação do curso - obra mimeografada):

... Se faço restrições ao ensino eminentemente prático (em que se preocupa fundamentalmente com a aquisição de conhecimento e o desenvolvimento de habilidades intelectuais), por considerá-lo excessivamente neurotizante, o que pensar de um curso (de pós-graduação (?)) desenvolvido em bases meramente inconformativas? Permita-me, Senhor Chefe, o luxo dessa opção: não me exija seja eu o responsável pela execução de um curso fundamentado na transformação do aluno em engenho caricato, em máquina apenas capacitada a memorizar e a armazenar informações. Em outras palavras, não me exija a responsabilidade por um curso de pós-graduação, que corre o risco de transformar uma disciplina de área de concentração em oficina de "professores" e ou "pesquisadores" bem informados e eruditos, mas sem quaisquer perspectivas para o trabalho científico, essencialmente criador. Estou convencido que deste modo, "nunca conseguiríamos substituir o vago pelo preciso, o artbitrário pelo sólido, a idéia abstrata pela concreta, o que não é possivel obter senão desenvolvendo a parte do fato, sem diminuir a da razão, mas, ao contrário, acrescentando-a".

\section{INSTITUCIONALIZAÇÃO DA PESQUISA NOS HOSPITAIS UNIVERSITÁRIOS}

Acreditamos que o Prof. Paulo de Góes, quando da realização do "IV Simpósio Nacional de Pós-Graduação nas áreas das Ciências da Saúde", realizado em Belo Horizonte, em novembro de 1978 (ao que tudo indica o espírito mudancista e modernizador da Faculdade de Medicina da UFMG se constrangeu com a antiga nomeação do Congresso e a alterou: Áreas de Saúde e não mais Áreas Biomédicas, como era sua designação até o 1111 , conseguiu resumir a idéia dominante sobre as atividades de pesquisas em nossos Hospitais Universitários. Depois de considerár à predominância da investigação biomédica no Brasil, em seus primórdios, como predominantemente realizada no terreno clínico: na Bahia a Escola Tropicalista, com F.G. Silva Lima, Otto Wucherer e J.L. Paterson; no Rio de Janeiro, com Felix Martins, Paulo Cantídio, Noronha Feital, Pereira Rego, Torres Homem e, a seguir com Francisco de Castro, Miguel Couto, Azevedo Sodré, A. Austrésilo, Clementino Fraga, admite ser forçoso reconhecer esta verdade: "a investigação clínica entre nós, quer em termos qualitativos quer quantitativos, não progrediu em paralelo com a pesquisa básica;", "não há dú vida", continua "que tal fato se deve à precariedade das condições hospitalares e à organização inadequada para os objetivos da pós-graduação: os hospitais que servem às escolas médicas, na maioria das vezes hospitais gerais, mal atendem eles ao ensino porque são Instituições de finalidade eminentemente assistencial".

Admitimos impraticável, considerando os objetivos a que ora nos prendemos, discorrer sobre os motivos que levaram o Prof. Belisário Campos, no mesmo Simpósio, a descrever, com minúncias, sobre a crise do Hospital Universitário no pais, em particular do Hospital das Clínicas da Faculdade de Medicina, onde exerce suas atividades de Professor Titular. No seu entender, "o rompimento do equilíbrio entre o ensino, a pesquisa e a assistência médica acarretou uma queda vertiginosa no desempenho do Hospital". Mais importante, entretanto, se nos afigura fixar aqui a impressão insuspeita de um emintente professor de Ciências Sociais, com largo conheci- 
mento do Hospital das Clínicas, onde trabalha e reside. Em seu livro "Processos Sociais", Prof. Geraldo Tolentino (Universidade Católica de Minas Gerais, 1978), assim se refere ao Hospital: . . . "Certas instituições, copiando modelos alienígenas, já estão entrando no século $X X I$. É o caso do sistema do Cuidado Progressivo do Paciente, implantado no Hospital das Clínicas, em Belo Horizonte, e o caso das técnicas pedagógicas importadas. Ambos dos Estados Unidos. Houve um aperfeiçoamento da organização e da administração hospitalar, mas decaíu o atendimento dos pacientes, como decaíram as condições de trabalho dos médicosresidentes. No exemplo da pedagogia, houve um aperfeiçoamento nas técnicas escolares, mas a remuneração do professorado, as suas condições de trabalho, a situação dos alunos e os conteúdos programáticos e curriculares permanecem inalterados. Tem faltado aos nossos planejadores, assessores, legisladores e executivos uma visão estrutural dos nossos problemas sociais. Gastamse recursos com a pintura da fachada do prédio, enquanto o interior deste edifício de trés andares (economia, classes, valores e cultura) continua mal dividido e mal arrumado, não proporcionando aos seus moradores melhores condições de vida. Mas, também, os próprios moradores de um andar desconhecem o funcionamento dos outros andares".

No Hospital Carlos Chagas, por outro lado, a pesquisa de há tempos encontrava-se institucionalizada. Esta conquista, dentre outras, foi, sem dúvida, o estímulo primeiro e maior a motivar um pequeno grupo de estudiosos da patologia brasileira a idealizar e a implantar o Curso de Pós-Graduação em Medicina Tropical. Assim, ao tempo da "modernização" do Hospital das Clínicas, o Hospital Carlos Chagas já se transformara, de fato, em área de concentração da pesquisa em medicina tropical. Desvendado o véu que encobria veladas ameaças de desativação do pequeno hospital, tornou-se imperioso sairmos à luta. Caso se concretizasse o desassiso da desativação, os motivos desta deveriam contrapor-se a um considerável volume de argumentos em contrário. Tudo debalde. Após um período de artimanhas administrativas, que não conseguiam ocultar a rejeição do hospital pelo complexo hospitalar do Hospital das Clínicas, o Carlos Chagas foi simplesmente fechado. Como se não bastasse o epílogo, recebeu destino ignorado todo o seu patrimônio acumulado em mais de 40 anos e, deste modo, criando sérios obstáculos ao cumprimento do Parecer N. 77/69, que estabelece os requisitos mínimos para o funcionamento de disciplinas de área de concentração em medicina.

Insensatez desmesurada ou retoque de teoria de modernização muito ambiciosa. Ainda que o Prof. J. Rodrigues Coura, em seu discurso de posse na Vice-Presidência de Pesquisa e Direção do Instituto Oswaldo Cruz (10.04.79) insistia não acreditar em reformas que destroem tudo para começar tudo do nada, que desprezam a experiência vivida para aplicar teorias não provadas; mesmo que muito ambiciosas, ou quaisquer outras que esqueçam as perspectivas históricas, porque estarão fadadas ao fracasso, consumou-se o fechamento. Meses depois, o mesmo hospital fora reaberto. Desta vez, com cheirinho de novo, limpo, todo engalandado como em dia de festa. Inaugurava-se, então o Ambulatório de Ginecologia. Ainda hoje o edifi. cio mantém, em dístico pomposo no frontispício, o nome de Carlos Chagas, que passa doravante a ser lembrado como o mais novo mecenas da tocoginecologia mineira.

Como estes fatos se consumaram quando das comemorações do centenário de nascimento de Carlos Chagas, fizemos publicar nos jornais a seguinte nota alusiva aos acontecimentos na Faculdade de Medicina da UFMG:

"A Faculdade de Medicina da Universidade Federal de Minas Gerais marcou a passagem do centenário de nascimento de Carlos Chagas com os seguintes eventos comemorativos:

- Desestímulo ao estudo das doenças infectuosas e parasitárias nos niveis de graduação e pós-graduação:

- Desincentivo às aspirações e objetivos do Curso de Pós-Graduação em Medicina Tropical, ao nível de Mestrado e Doutorado; Desagregação e dispersão do grupo docente, de estudiosos e de pesquisadores em doenças infectuosas e parasitárias;

- Desativação e posterior fechamento do Hospital Carlos Chagas, centro polariza. dor de estudos e pesquisas da patologia brasileira;

- Desencanto do pessoal discente que, inevitavelmente, passa a encarar o estudo da patologia representativa de nossas comunidades como se brasileira não fosse.

A análise detida destes fatos e de outros, cuja descrição seria no mínimo cansativa, em 18.10.77 levou-nos a endereçar ao Colegiado de Coordenação Didática do Curso uma proposta clara e incisiva, como convinha. Propunhamos, uma vez ouvida a Coordenação do Ensino e Pesquisa da UFMG, a revisão dos objetivos do Curso de Pós-Graduação (Mestrado e Doutorado) solicitando todas as providênciais necessárias e 
cabiveis ao normal funcionamento do Curso ou, se fosse o caso, a suspensão do mesmo, conforme o estabelecido no inciso 14.1 das Normas Gerais de Pós-Graduação (Resolução n? 0\$/74, de 04.05.73, da Coordenadoria do Ensino e Pesquisa). Apesar de haver recebido aprovação unânime do Colegiado de Curso, a proposição, por certo considerada anódina, se não inoportuna, deve ter tido seu endereçamento utilitariamente desviado. Desapareceu. Extraviou-se, quem sabe, a caminho ou perdeu-se nos meandros de uma burocracia tornada conveniente e necessária.

Entrementes, fatos também ininteligiveis se passavam no Curso de Pós-Graduação em Doenças infecciosas da UFRJ. É deveras estranho como a ocorrência se dava justamente num Curso que, considerado em seu conjunto, possuia condições excepcionais para atender aos objetivos da Pós-Graduação em seu senso estrito. Senão vejamos:

1. Seu idealizador e primeiro Coordenador - ilustre Prof. José Rodrigues Coura, com larga experiência em pós-graduação, como estudante que foi do The London School of Hygiene and Tropical Medicine, Universidade de Londres, em outras Universidades do exterior, a par de uma intensa atividade docente e de pesquisa, conseguiu reunir um Grupo Docente categorizado e motivado para a atividade pós-graduada. Em seguida tendo como Coordenador a Profa Léa Camillo - Coura e como Coordenadores adjuntos os Profs. Paulo Francisco de Almeida Lopes, Heleno Tinoco de Carvalho e Walter Tavares, o Curso conta com 20 Docentes, sendo 7 Livre-Docentes, 2 Doutores, 8 Mestres e 3 Professores Convidados. Até 1979, formou 25 Mestres e 1 Doutor.

2. O desenvolvimento da criatividade cientifica remonta à época do saudoso Prof. José Rodrigues da Silva, ao formar um grupo de jovens professores e pesquisadores com visão de saúde pública, em particular da patologia tropical. Sedimentou-se, a seguir, em seu Corpo Docente, sob compromisso de seu austero idealizador, e numa infra-estrutura constituida de 12 Departamentos Especializados do Instituto Oswaldo Cruz (em credenciamento com a UFRJ), com o Instituto Biomédico, Instituto de Microbiologia, Instituto de Biofísica, onde militam professores e pesquisadores dos mais renomados do país: Professores Leônidas de Mello Deane, Maria P. Deane, Luiz Fernando Rocha Ferreira, Ernesto Hofer, A.T. Londero, Herman G. Schatzmayr, Bernardo Galvão Castro, Zilton Andrade, Wladimir Lobato Paraense, Ítalo Suassuna, Domingos de Paola, para citarmos apenas alguns dentres os professores coordenadores de disciplina e convidados.

3. O Hospital Universitário da UFRJ, é justo e pertinente o registro, foi um dos primeiros, a incluir a pesquisa dentre os objetivos instituicionais e vem realizando, com pertinaz atuação do Prof. José Rodrigues Coura, um trabalho sistemático para que os mesmos sejam plenamente atendidos. Neste Hospital, com capacidade de 500 leitos, 50 são especialmente destinados às doenças infecciosas e parasitárias. As atividades de pesquisa do Hospital Universitário são permanentemente supervisionadas por uma Comissão de Investigação Científica, com membros eleitos pelo Conselho Técnico-consultivo do Hospital, órgão de administração superior. No desempenho de suas funções, a Comissão de Investigação Científica procedeu, inicialmente, à avaliação das condições gerais do Hospital, identificando os pormenores que poderiam eventualmente ser menos favoráveis à pesquisa. Elaborou, a seguir, pontos de referência para a elaboração de uma política científica do Hospital e estabeleceu roteiros e normas para a elaboração de projetos de pesquisa.

Por último, tivemos, juntamente com os eminentes Professores Jair Xavier Guimarães e Vicente Amato Neto, a honrosa incubência de cumprir designação feita pelo Exmo. Sr. Prof. Lafayette de Azevedo Pondé, Digníssimo Presidente do Conselho Federal da Educação, constituindo a Comissão Verificadora para fins de credenciamento do Curso de Mestra. do e Doutorado em Doenças Infecciosas e Parasitárias da UFRJ.

A par de minucioso estudo das atividades desenvolvidas pelo referido Curso, durante o periodo 1974-1979, nosso Relatório pontificou a seguinte conclusão:

"Em conclusão, a Comissão Verificadora considera que o Curso de Pós-Graduação em Medicina - área de concentração em Doenças Infecciosas e Parasitárias - a nivel de Mestrado e Doutorado - da Faculdade de Medicina da Universidade Federal do Rio de Janeiro, não somente está plenamente capacitado a ser recredenciado pelo Colendo Conselho Federal de Educação, como é altamente merecedor de todo o apoio do Ministério da Educação e Cultura e dos órgãos governamentais financiadores da pós-graduação, a fim de encontrar melhores condições $\mathfrak{k}$ ra continuar nesse importantíssimo mister - qual seja o de formar Docentes qualificados para área tão importante e tão carente no Brasil".

Para a surpresa de todos os direta ou indire- 
tamente envolvidos no Curso de Pós-Graduação em Doenças Infecciosas $\mathrm{d}$ r UFRJ, o Conselho Federal de Educação, em Parecer 0035/81, Processo 2353/79 negou o recredenciamento do Curso.

Pasmem agora todos os que me honram, em benevolente tolerância, como ouvıntes de um relato de fatos que, pela tônica de seus desconcertos $\mathrm{e}$ incongruências, só fazem por desmerecer a Universidade Brasileira. Tampouco foi de meu agrado a tarefa de relatá-los. Mas não posso evitar que se pasmem, porque ao mesmo tempo em que descredencia um Curso de Pós-Graduação que, recr nhecidamente, é o melhor na área em todo o pais, onde se pontifica um austero propó. sito de formar e qualificar docentes em campo tão carente, o Curso de Pós-Graduação em Medicina Tropical da faculdade de Medicina da UFMG sobrevive incólume.

Não nos parece relevante incitar o debate em torno dos erros da Pós-Gradução em Medicina Tropical, não importa que procedência tenham, "se a própria história da ciência é uma história de erros". É momento de identificar e procurar soluções para as distorções encontradas. Importa, pois, excitar o sitema e analisar criticamente todo o seu processo, com a inteção de corrigirIhes os erros. Estamos convencidos, também, que atrasaremos todo um processo que visa ao refreamento do obscurantismo, da injustiça e do desamor se nos obstinarmos em querelas, que nada constróem, mas que têm contribuído para eleminar toda a motivação ao trabalho produtivo e criador. No particular aos dois Cursos de Pós-Graduação aqui mencionados, em particular o da nossa Faculdade de Medicina, não podemos paralizá-los, sob qualquer pretexto; tampouco, devemos entorpecer as potencialidades jovens que ai estão, sob o risco de acarretarmos danos irreparáveis às nossas instituições. Precisamos, isto sim, urgentemente, reconstruir a paz interna e fazer renascer o entusiasmo e a vontade de trabalho nos escalões docente, discente e administrativo.

\section{LITERATURA CONSULTADA}

1. AZEVEDO, F. de Obras Completas. Principios de Sociologia. $\quad 8^{a}$ ed. Edição $\mathrm{Me}$ ihoramentos, São Paulo, 1958.

2. CARVALHO, G.I. Ensino Superior. Legislação e Jurisprudência. 4a a ed., Rio de Janeiro, 1973.

3. CHATEAU, J. Os Grandes Pedagogistás. Companhia Editora Nacional, São Paulo, 1978.
4. COURA, J.R. Relevância do Ensino da Medi cina Preventiva na Formação do Profissional de Saúde. Rev. Soc. Bras. Med. Trop. $6: 105-113,1972$.

5. COURA, J.R. Discurso de Posse como VicePresidente de Pesquisa da Fundação Oswaldo Cruz, Rio de Janeiro, 1979.

6. COURA, J.R. Retormas do ensıno e de currículos e o ensino das doenças infecciosas e parasitárias no Brasil Rev. Bras. Ed. Médicas 4: 39-46, 1980.

7. NEVES, J. Considerações Gerais sobre o /II Simpósio Nacional de Pós-Graduação nas Áreas Biomédicas. Resumos do III Simpósio Nacional de Pós-Graduação nas Áreas Biomédicas, 6 a 9 de abril, Ribeirão Preto, São Paulo, 1975.

8. NEVES, J. Há Chagas nestas Achegas (Reflexões e Correspondências). Monografia miografada. 436 pp, Belo Horizonte, 1979.

9. NEVES, J. A Verdade sobre a Crise da Pós- Graduacão em Medicina Tropical da Faculdade de Medicina da UFMG (O Processo de Desativação do Cursol. Monojrafia mimeografada, 80 p., Belo Horizonte, 1980.

10. NEVES, J. latrogenia em infectologia: 'J na questão de educação médica. Trabalho apresentado ao I Congresso de Infectologia dos $\mathrm{Pa}$ ises de Lingua Portuguesa, - Camboriú, SC, 04-09, 1981 (em publicação em Educación Médica y Salud, OMSI.

11. PRINCE, G. И. Prática da Criatividade. (Manual de Solucionamento Dinâmico de Grupo). Ed. Cultrix. São Paulo, 1975.

12. QUARTO SIMPÓSIO NACIONAL DE PÓS-GRADUAÇÃO NAS ÁREAS DAS CIÊNCIAS DA SAÚDE.

08.11 novembro, Belo Horizonte, $M G$, 1978.

13. SCHWARTZMAN, S. Formação da Comunidade Cientifica no Brasil. Financiadora de Estudos e Projetos (FINEP), Rio de Janeiro, 1979.

14. SEMINÁRIO REGIONAL DA ABEM. Maceió, AL, 10.11 agosto, 1979. Rev. Bras. Ed. Médica 3:45-94, 1979.

15. SOCIEDADE BRASILEIRA DE MEDICINA TROPICAL, Assembléia Geral, Natal, RN, 06, fevereiro, 1980, In Coura, J. R., 1980.

16. TOLENTINO, G. Processos Sociais. ed. Faculciade Católica de Minas Gerais, 1978. 